\title{
Zur Person des Autors
}

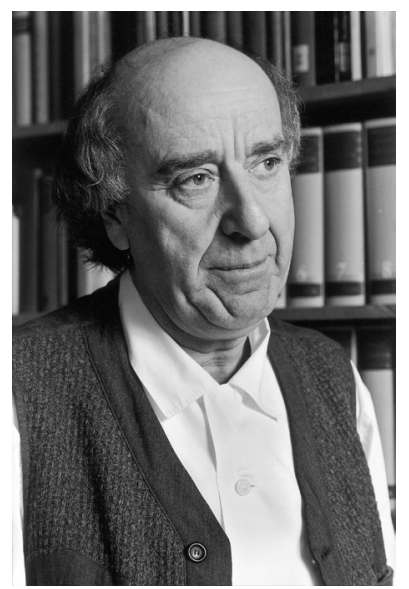

Uwe Wesel, geb. 1933 in Hamburg, dort Abitur und Studium der Klassischen Philologie, danach der Rechtswissenschaft in München, wo er von 1961 bis 1968 Assistent an der Juristischen Fakultät bei Wolfgang Kunkel gewesen ist. Dort erfolgten auch die üblichen juristischen Examina und 1968 eine Habilitation für Römisches Recht und Bürgerliches Recht. Seit 1968 ist er (nunmehr emeritierter) Professor an der Freien Universität Berlin, deren 1. Vizepräsident er 1969 - 1973 war. Zudem ist er Mitglied des P. E. N.-Zentrums Deutschland.

Wichtigste Veröffentlichungen:

Der Mythos vom Matriarchat (1980), Juristische Weltkunde (1984), Frühformen des Rechts in vorstaatlichen Gesellschaften (1985), Der HoneckerProzeß (1994), Die Hüter der Verfassung (1996), Der Gang nach Karlsruhe (2004), Mitarbeit in den Zeitschriften «Kritische Justiz», «Kursbuch» und «Die Zeit».

Bücher bei C.H.Beck:

Geschichte des Rechts (1. Auflage 1997, 4. Auflage in Vorbereitung für November 2013)

Recht, Unrecht und Gerechtigkeit (2003)

Geschichte des Rechts in Europa (2010)

Fast alles was Recht ist (9. Auflage in Vorbereitung für 2014), 
https://doi.org/10.17104/9783406684883-591, am 26.04.2023, 11:56:37

Open Access - (c) EY - http://www.beck-elibrary.de/agb 